\title{
Attitudes and opinions of US neurosurgical residents toward research and scholarship: a national survey
}

\author{
${ }^{*}$ Michael Karsy, MD, PhD, MSc, ${ }^{1}$ Fraser Henderson Jr., MD, ${ }^{2}$ Steven Tenny, MD, MPH, MBA, ${ }^{3}$ \\ Jian Guan, MD, ${ }^{1}$ Jeremy W. Amps, MD, ${ }^{4}$ Allan H. Friedman, MD, ${ }^{5}$ Alejandro M. Spiotta, MD, ${ }^{2}$ \\ Sunil Patel, MD, ${ }^{2}$ John R. W. Kestle, MD, ${ }^{1}$ Randy L. Jensen, MD, PhD, ${ }^{1}$ and \\ William T. Couldwell, MD, PhD'
}

\begin{abstract}
${ }^{1}$ Department of Neurosurgery, Clinical Neurosciences Center, University of Utah, Salt Lake City, Utah; ${ }^{2}$ Department of Neurosurgery, Medical University of South Carolina, Charleston, South Carolina; ${ }^{3}$ Division of Neurosurgery, University of Nebraska Medical Center, Omaha, Nebraska; ${ }^{4}$ Department of Neurosurgery, Cleveland Clinic, Cleveland, Ohio; and ${ }^{5}$ Department of Neurosurgery, Duke University, Durham, North Carolina
\end{abstract}

OBJECTIVE The analysis of resident research productivity in neurosurgery has gained significant recent interest. Resident scholarly output affects departmental productivity, recruitment of future residents, and likelihood of future research careers. To maintain and improve opportunities for resident research, the authors evaluated factors that affect resident attitudes toward neurosurgical research on a national level.

METHODS An online survey was distributed to all US neurosurgical residents. Questions assessed interest in research, perceived departmental support of research, and resident-perceived limitations in pursuing research. Residents were stratified based on number of publications above the median $(A M ; \geq 14)$ or below the median $(B M ;<14)$ for evaluation of factors influencing productivity.

RESULTS A total of 278 resident responses from 82 US residency programs in 30 states were included (a $20 \%$ overall response rate). Residents predominantly desired future academic positions (53.2\%), followed by private practice with some research (40.3\%). Residents reported a mean \pm SD of $11 \pm 14$ publications, which increased with postgraduate year level. The most common type of research involved retrospective cohort studies (24\%) followed by laboratory/benchtop (19\%) and case reports (18\%). Residents as a group spent on average $14.1 \pm 18.5$ hours (median 7.0 hours) a week on research. Most residents (53.6\%) had $\geq 12$ months of protected research time. Mentorship (92.4\%), research exposure $(89.9 \%)$, and early interest in science $(78.4 \%)$ had the greatest impact on interest in research while the most limiting factors were time $(91.0 \%)$, call scheduling $(47.1 \%)$, and funding/grants $(37.1 \%)$. AM residents cited research exposure ( $p$ $=0.003)$, neurosurgery conference exposure $(p=0.02)$, formal research training prior to residency $(p=0.03)$, internal funding sources $(p=0.05)$, and software support $(p=0.02)$ as most important for their productivity. Moreover, more productive residents applied and received a higher number of $<\$ 10,000$ and $\geq \$ 10,000$ grants $(p<0.05)$. A majority of residents (82.4\%) agreed or strongly agreed with pursuing research throughout their professional careers. Overall, about half of residents (49.6\%) were encouraged toward continued neurosurgical research, while the rest were neutral (36.7\%) or discouraged (13.7\%). Free-text responses helped to identify solutions on a departmental, regional, and national level that could increase interest in neurosurgical research.

CONCLUSIONS This survey evaluates various factors affecting resident views toward research, which may also be seen in other specialties. Residents remain enthusiastic about neurosurgical research and offer several solutions to the ever-scarce commodities of time and funding within academic medicine.

https://thejns.org/doi/abs/10.3171/2018.3.JNS172846

KEYWORDS neurosurgery; residency; research; academic medicine; career

ABBREVIATIONS AM = number of publications above the median; $\mathrm{BM}=$ number of publications below the median; HHMI = Howard Hughes Medical Institute; IQR = interquartile range; NREF = Neurosurgery Research and Education Foundation; PGY = postgraduate year; RUNN = Resident Update in Neuroscience for Neurosurgeons. SUBMITTED November 13, 2017. ACCEPTED March 6, 2018.

INCLUDE WHEN CITING Published online August 17, 2018; DOI: 10.3171/2018.3.JNS172846.

* M.K. and F.H. contributed equally to this work. 
$\mathrm{R}$ ESEARCH productivity in neurosurgery, with its capacity to improve patients' lives, remains an important and timely topic. Multiple publications have evaluated and ranked the scholarly production of neurosurgical programs. ${ }^{1,5,11,12,14,15,22,23,26}$ Scholarly output affects program accreditation, program reputation, grants, future resident recruitment, and academic promotion. In addition, bibliometrics in neurosurgery are increasingly reported. Publications by residents, attendings, and entire programs have been quantified to understand the overall academic output of neurosurgery. A recent literature review of factors affecting resident choices in academic medicine careers suggested a lack of clarity in understanding resident career choices and recommended further study. ${ }^{2}$

Multiple studies have supported the idea that resident productivity correlates strongly with overall neurosurgical department productivity. ${ }^{10,22}$ Applicants to neurosurgery remain academically competitive among the pool of medical students as assessed by mean board scores, scholastic performance, and research productivity. ${ }^{19}$ However, the effect of neurosurgical training on the research endeavors and future career aspirations of residents remains unknown. The factors that affect scholarship on a departmental and national level have not yet been explored. We sought to survey US neurosurgical residents regarding interest in research, limitations of pursuing research, and potential methods for improving overall resident research.

\section{Methods \\ Survey Design}

A survey was designed to analyze resident opinions toward research in neurosurgery residency. Research was defined as the pursuit of new knowledge or the improved application of existing knowledge. Study data were collected and managed using the Research Electronic Data Capture (REDCap) tool (version 7.0.19). Questions were generated and evaluated via a pilot survey administered to the neurosurgical residents at the University of Utah and Medical University of South Carolina. Feedback on questions was obtained from residents, senior neurosurgical faculty (J.W.A., A.H.F., A.M.S., S.P., J.R.W.K., R.L.J., W.T.C.), course directors at the Resident Update in Neuroscience for Neurosurgeons (RUNN; A.H.F.), members of the Council of State Neurosurgical Societies (S.T., J.W.A.), and research committee members of the Society of Neurological Surgeons (E. Antonio Chiocca, MD, PhD). For the pilot survey, 13 resident responses were obtained over 40 questions (Supplemental Material 1). This pilot question sample was then expanded to a list of 58 questions (Supplemental Material 2). Free-response prompts were available to provide comments not otherwise captured in the survey. The survey was disseminated to 109 programs via an emailed link to the residency program coordinators and a reminder sent to program directors 2 weeks later. The data collection period was from August 25, 2017, until September 25,2017. The survey was anonymous, and participants received a \$15 Amazon gift card at the completion of the survey.

\section{Analysis}

Survey results were classified as demographic variables, research experiences prior to or during residency, details of presented research at conferences, research funding, limiting factors in residency, and programmatic support of research. A free-text response was used to evaluate potential solutions to the limitation. Several bibliometric parameters were assessed from prior studies. Mean resident h-index for a program, the mean number of resident publications on Scopus by program, and program rank by resident h-index were acquired from a 2017 study by Sarkiss et al. ${ }^{22}$ Program rank by faculty h-index and the total number of faculty were assessed by a 2014 study from Khan et al. ${ }^{12}$ The h-index defines a scholar as someone who has published $\mathrm{h}$ papers with at least $\mathrm{h}$ number of citations, thus reflecting both the number of publications and theoretical value of those publications. Published parameters from these studies were entered for each resident depending on their stated program. Several newer residency programs did not have available bibliometric variables. Residents were also characterized by the number of self-reported peer-reviewed publications to assess factors affecting publication rate. Those with numbers of publications above the median (AM; $\geq 14$ publications) were compared with those with below the median $(\mathrm{BM} ;<14$ publications). For evaluation of opinions along a 5-tier response (strongly disagree, disagree, neutral, agree, and strongly agree), responses were weighted to allow comparison of $\mathrm{AM}$ and $\mathrm{BM}$ residents by $\mathrm{t}$-test.

The survey data were compiled at the end of data collection, anonymized, and analyzed using SPSS (version 20.0 , IBM). Means \pm standard deviations and percentages were generated for continuous and discrete variables where appropriate. Continuous variables were compared via Student t-test or linear regression and discrete variables were analyzed by chi-square test or Fisher's exact test. Median values were evaluated by the Mann-Whitney U-test. A predetermined $\mathrm{p}$ value $<0.05$ was considered statistically significant.

\section{Results \\ Demographics}

From a total of 281 responses obtained from 82 US residency programs in 30 states resulting in a $20 \%$ response rate, the results were narrowed to 278 responses because 3 surveys were duplicated. The geographic location of residency programs with respondents is shown in Fig. 1 and represents a national distribution of programs. The distributions of responses by postgraduate year (PGY), subspecialty goal, and future practice preference are show in Table 1.

Residents were divided into two groups (AM vs BM) to assess factors affecting scholarly productivity (Table 1). A total of $146 \mathrm{BM}$ residents and $132 \mathrm{AM}$ residents were identified. A higher proportion of later PGY levels were noted in the AM group compared with the BM group ( $\mathrm{p}=$ $0.02)$. No difference in subspecialty interest $(p=0.87)$ was noted between the groups. The AM residents were more likely to prefer an academic career $(p=0.0001)$, train in the West and Northeast $(\mathrm{p}=0.03)$, and have recent publications $(p=0.0001)$. Unsurprisingly, AM residents also 


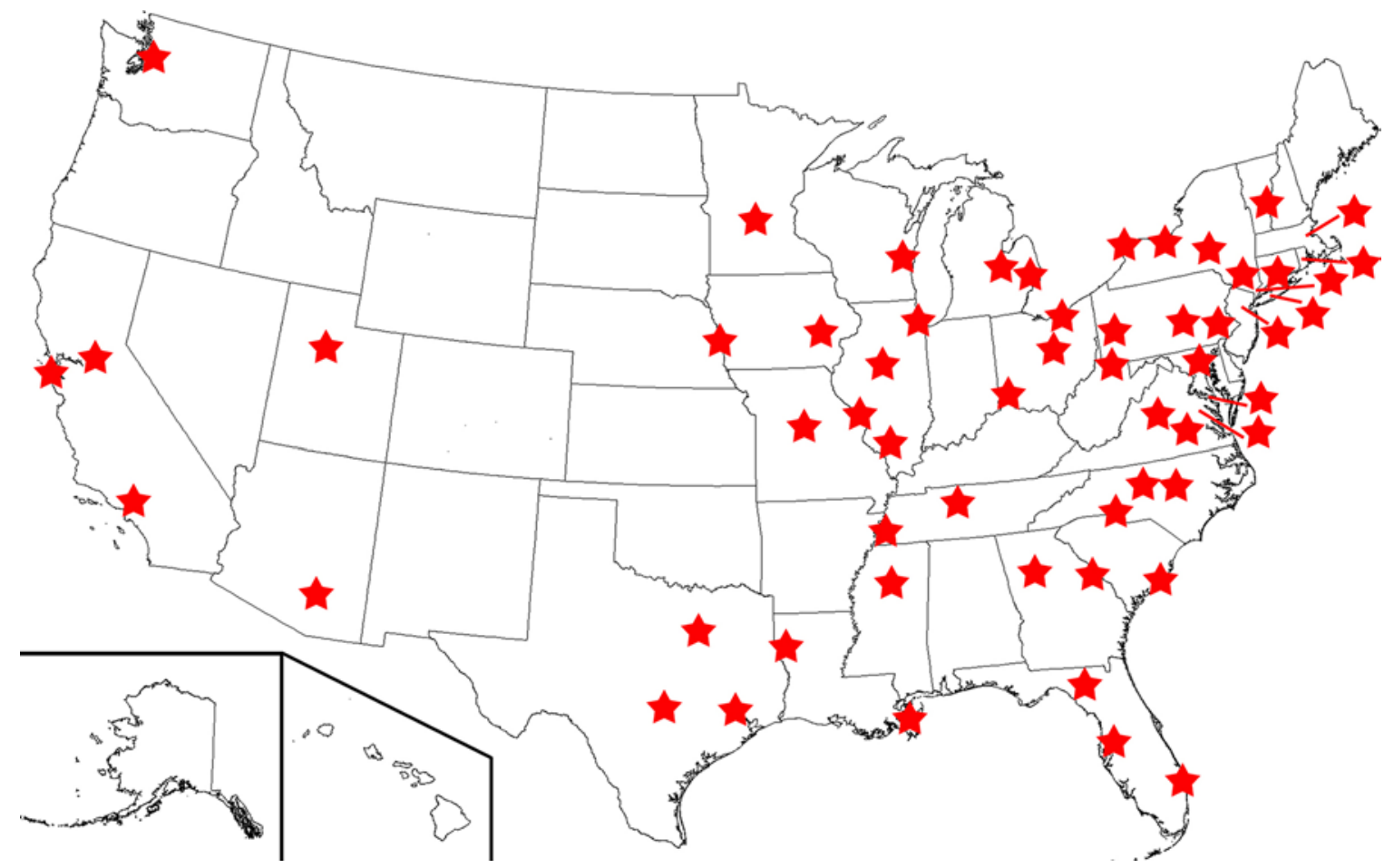

FIG. 1. Representative map of US neurosurgical residency programs with survey responses. A map of 82 US residency programs with at least 1 resident who responded to the survey is shown. Specific numbers of respondents from different programs are not shown. In some locations, multiple institutions may have responded to the survey but are only represented by 1 star. Figure is available in color online only.

had a higher average h-index $(\mathrm{p}=0.0001)$, and a higher number of papers listed in Scopus $(p=0.0001)$. AM residents were in programs with a larger number of faculty $(\mathrm{p}=0.0001)$, a higher median program rank by resident h-index $(\mathrm{p}=0.0001)$, and a higher median program rank by faculty $\mathrm{H}$-index $(\mathrm{p}=0.0001)$.

\section{Publications and Research Time}

The distribution of research project types is shown in Fig. 2A. Residents had written a mean of $11 \pm 14$ papers (median $=7$ ) by the time of the survey (25th interquartile range $[\mathrm{IQR}]=3,75$ th $\mathrm{IQR}=15$; Fig. $2 \mathrm{~B}$ ). The number of resident publications correlated positively with PGY level $(\beta=1.7, R=0.23, p<0.0001$, linear regression; Fig. $2 C)$. There were a number of outliers in terms of both publication number and research time. Eleven residents, exclusively later-stage residents ( $\geq$ PGY4) had $>39$ publications (2 standard deviations from the mean). Residents spent on average $14.1 \pm 18.5$ self-reported hours (median $=7.0$ ) per week on research (Fig. 2D). Most residents (53.6\%) stated they had $\geq 12$ months of protected research time (Fig. 2E). A distribution of hours spent on research per week and total number of publications shows a strong positive correlation $(\beta=0.132, R=0.22, p=0.03$, linear regression; Fig. 2F). AM residents spent a significantly greater number of hours on research than BM residents $(18.5 \pm 21.0 \mathrm{vs}$ $10.2 \pm 14, p=0.0001$; Table 2). There was no difference in the number of dedicated research months $(\mathrm{p}=0.11)$, with $51.5 \%$ of AM residents and $58.9 \%$ of PM residents having $\geq 12$ months of protected time.

\section{Research Resources, Presentations, and Funding}

Resident responses regarding research experiences, research presentation, and success with funding were collected to evaluate where residents learned the scientific process and where avenues for improvement could be found (Table 2). Categories were not mutually exclusive and single residents could have obtained multiple avenues of research experience. Among all factors, rates of completion of a dedicated research year $(p=0.001)$, research fellowships $(\mathrm{p}=0.0001)$, and postdoctoral fellowships $(p=0.0001)$ were significantly higher among AM residents. Residents without formal graduate research training were significantly more likely to be in the BM group ( $\mathrm{p}$ $=0.002)$. AM residents reported a higher number of presentations at national $(p=0.0001)$, regional $(p=0.0001)$, and international $(p=0.0001)$ meetings. Similarly, AM residents had greater numbers of submitted $(p=0.0001)$ and received $(\mathrm{p}=0.0001)$ grants for $<\$ 10,000$ as well as submitted $(\mathrm{p}=0.0001)$ and received $(\mathrm{p}=0.0001)$ grants for $\geq \$ 10,000$. Whereas approximately half of residents (49.6\%) were more enthusiastic to pursue research since starting residency, the other half were either unchanged $(36.7 \%)$ or discouraged (13.7\%); no significant difference in attitude was observed between the AM and BM groups.

\section{Limiting Factors in Neurosurgical Resident Research}

Important factors limiting resident research as well as residency program initiatives to improve research endeavors were explored by simple "yes" and "no" responses (Table 3). The 3 factors cited as most important in af- 
TABLE 1. Distribution of neurosurgery resident respondents

\begin{tabular}{|c|c|c|c|c|}
\hline Variable & All Residents $(n=278$ ) & BM Residents $(n=146)$ & AM Residents $(n=132)$ & $\mathrm{p}$ Value \\
\hline PGY & & & & 0.02 \\
\hline 1 & $49(17.6)$ & $32(21.9)$ & $17(12.9)$ & \\
\hline 2 & $41(14.7)$ & $23(15.8)$ & $18(13.6)$ & \\
\hline 3 & $42(15.1)$ & $28(19.2)$ & $14(10.6)$ & \\
\hline 4 & $45(16.2)$ & $28(19.2)$ & $17(12.9)$ & \\
\hline 5 & $52(18.7)$ & $18(12.3)$ & $34(25.8)$ & \\
\hline 6 & $30(10.8)$ & $10(6.8)$ & $20(15.2)$ & \\
\hline 7 & $19(6.8)$ & $7(4.8)$ & $12(9.1)$ & \\
\hline Current subspecialty interest & & & & 0.87 \\
\hline Spine & $68(24.5)$ & $38(26.0)$ & $30(22.7)$ & \\
\hline Tumor/neurooncology & $61(21.9)$ & $29(19.9)$ & $32(24.2)$ & \\
\hline Endovascular & $43(15.5)$ & $21(14.4)$ & $22(16.7)$ & \\
\hline Pediatric & $35(12.6)$ & $19(13.0)$ & $16(12.1)$ & \\
\hline Functional & $32(11.5)$ & $17(11.6)$ & $15(11.4)$ & \\
\hline Skull base & $32(11.5)$ & $17(11.6)$ & $15(11.4)$ & \\
\hline Trauma/critical care & $5(1.8)$ & $3(2.1)$ & $2(1.5)$ & \\
\hline Peripheral nerve & $2(0.7)$ & $2(1.4)$ & $0(0.0)$ & \\
\hline Current practice type interest & & & & 0.0001 \\
\hline Academics & $148(53.2)$ & $59(40.4)$ & $89(67.4)$ & \\
\hline Private practice $w /$ some research & $112(40.3)$ & $74(50.7)$ & $38(28.8)$ & \\
\hline Private practice & $15(5.4)$ & $11(7.5)$ & $4(3.0)$ & \\
\hline Other & $3(1.1)$ & $2(1.4)$ & $1(0.8)$ & \\
\hline Region & & & & 0.03 \\
\hline Midwest & $87(31.3)$ & $52(35.6)$ & $35(26.5)$ & \\
\hline Southeast & $80(28.8)$ & $47(32.2)$ & $33(25.0)$ & \\
\hline Northeast & $78(28.1)$ & $37(25.3)$ & $41(31.1)$ & \\
\hline West & $24(8.6)$ & $7(4.8)$ & $17(12.9)$ & \\
\hline Mountain & $9(3.2)$ & $3(2.1)$ & $6(4.5)$ & \\
\hline Author of publication last yr & $223(80.2)$ & $99(67.8)$ & $124(93.9)$ & 0.0001 \\
\hline Mean resident $h$-index \pm SD & $2.6 \pm 2.3$ & $2.2 \pm 1.5$ & $3.0 \pm 1.7$ & 0.0001 \\
\hline Mean no. of Scopus documents \pm SD & $7.8 \pm 6.2$ & $6.0 \pm 5.5$ & $9.7 \pm 7.0$ & 0.0001 \\
\hline Median program rank by resident $h$-index & 35 & 50 & 25 & 0.0001 \\
\hline Median program rank by faculty h-index & 47 & 52 & 23 & 0.0001 \\
\hline Mean no. of faculty \pm SD & $12.9 \pm 12.0$ & $13.3 \pm 5.5$ & $16.2 \pm 5.2$ & 0.0001 \\
\hline
\end{tabular}

Data are reported as number (\%) unless otherwise indicated. Boldface type indicates statistical significance.

fecting an interest in research were mentorship (92.4\%), research exposure (89.9\%), and early interest in science (78.4\%). For AM residents, research exposure $(\mathrm{p}=0.003)$, neurosurgery conference exposure $(p=0.02)$, and formal research training prior to residency $(p=0.03)$ were more important than they were for BM residents. The programmatic factors that were more likely to be cited by residents in the AM group included internal departmental funding $(p=0.05)$ and software support $(p=0.02)$.

Residents were asked to select from a list the three most limiting factors for their future research opportunities in residency. Time $(91.0 \%)$, call scheduling $(47.1 \%)$, and funding/grants $(37.1 \%)$ were the most commonly selected choices. AM and BM residents agreed that time $(\mathrm{p}=$ $0.4)$ and call schedules $(p=0.96)$ were important limiting factors. Interestingly, funding/grants $(\mathrm{p}=0.02)$ was more likely cited as a critical factor by AM residents. Difficulty in finding novel research topics was more likely in the BM residents $(p=0.02)$. No differences in other factors were identified.

\section{Opinions Regarding Resident Research in Neurosurgery}

Resident perceptions toward research and overall interest were evaluated on a five-tier scale (Fig. 3). A total of $82.4 \%$ of residents agreed or strongly agreed with interest in pursuing research throughout their professional careers. Most $(87.4 \%)$ agreed with wanting to present research at local or national meetings. Most residents (72.7\%) also agreed that a strong research foundation in residency would help with landing a job as an attending physician, 

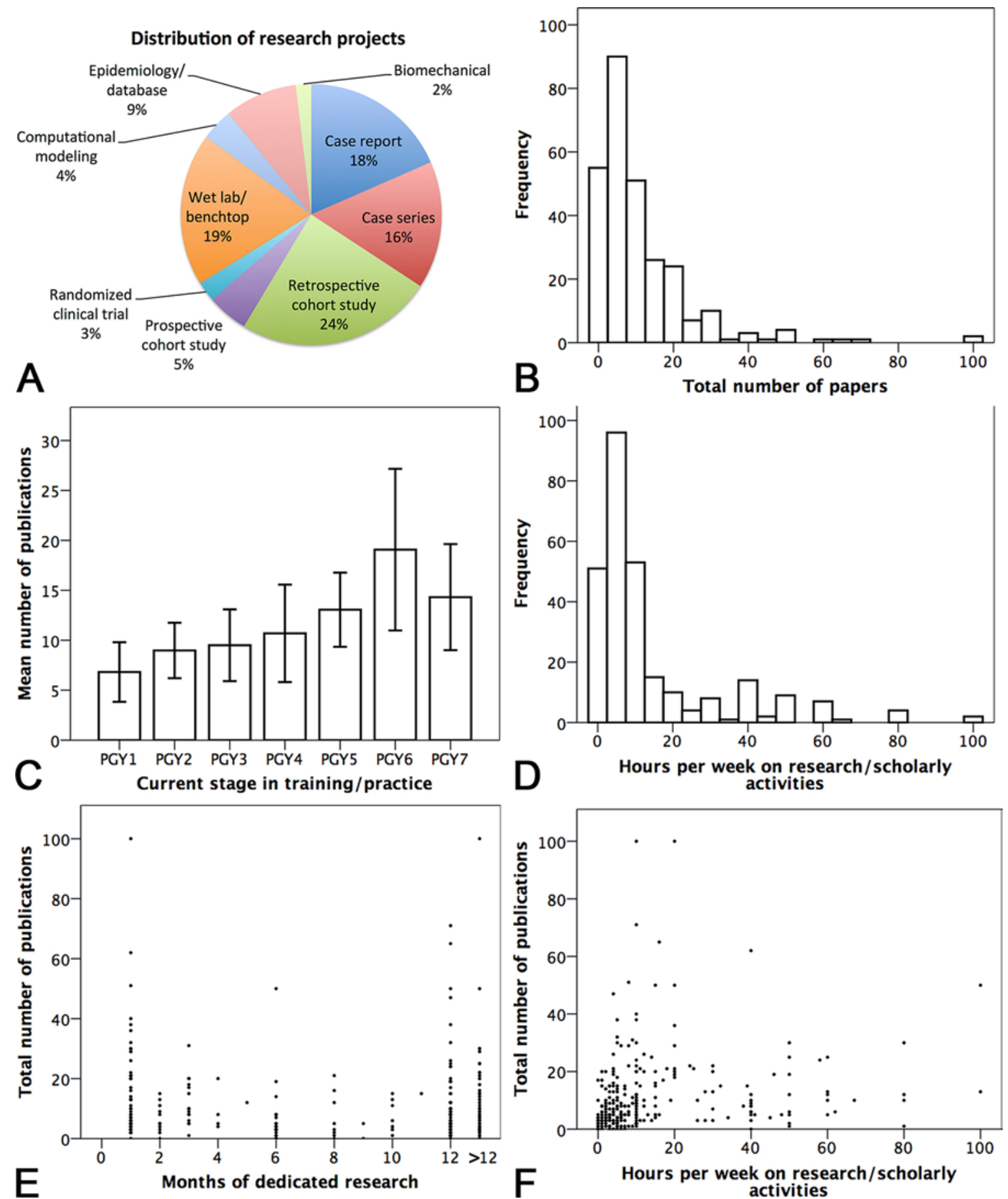

FIG. 2. Distribution of research projects, publications, and scholarly time. A: The distribution of participant research projects included retrospective cohort studies $(24 \%)$, wet lab/benchtop (19\%), case reports (18\%), case series (16\%), epidemiological/database $(9 \%)$, prospective cohort studies $(5 \%)$, computational modeling $(4 \%)$, randomized clinical trials $(3 \%)$, and biomechanical studies $(2 \%)$. Reviews, opinion pieces, and editorials were not included. B: The distribution of resident publications showed a rightward shift in which a limited number of residents wrote large volumes of papers. Residents wrote an average of $11 \pm 14$ manuscripts overall and this information can be comparative among residents and programs seeking insight into adequate research requirements for their trainees. C: There was a significant increase in the mean number of publications with increased PGY level ( $\beta=1.7$, $p<0.0001$, linear regression). For PGY1 to PGY7 years, the mean \pm standard deviation number of publications was $7 \pm 10,9 \pm 9$, $10 \pm 12,11 \pm 16,13 \pm 13,19 \pm 21$, and $14 \pm 11$, respectively. D: A rightward shift to the distribution of dedicated research hours per week was also seen. On average, residents spent $14.1 \pm 18.5$ hours weekly toward research or other scholarly activities. $E$ and F: Months of dedicated research $(E)$ and hours spent per week $(F)$ were compared with scholarly production. A bimodal distribution for dedicated research time was observed. Although outlying subjects showed significant time devotion or productivity, most residents clustered around 10 hours a week and 10 publications at the time of the survey. Figure is available in color online only. 
TABLE 2. Research experiences and exposure

\begin{tabular}{|c|c|c|c|c|}
\hline Variable & All Residents $(n=278)$ & BM Residents $(n=146)$ & AM Residents $(n=132)$ & $\mathrm{p}$ Value \\
\hline Research/scholarly hrs/wk & $14.1 \pm 18.5$ & $10.2 \pm 14.9$ & $18.5 \pm 21.0$ & 0.0001 \\
\hline \multicolumn{5}{|l|}{ Research experience } \\
\hline $\begin{array}{l}\text { Research/clinical training courses (e.g., AANS/CNS, } \\
\text { RUNN course, Boot Camp) }\end{array}$ & $120(43.2)$ & $56(38.4)$ & $64(48.5)$ & 0.09 \\
\hline Cadaver courses & $113(40.6)$ & $54(37.0)$ & $59(44.7)$ & 0.2 \\
\hline Clinical science research conference & $105(37.8)$ & $50(34.2)$ & $55(41.7)$ & 0.2 \\
\hline Basic science research conference & $82(29.5)$ & $40(27.4)$ & $42(31.8)$ & 0.4 \\
\hline Dedicated research year & $83(29.9)$ & $31(21.2)$ & $52(39.4)$ & 0.001 \\
\hline Online videos & $67(24.1)$ & $32(21.9)$ & $35(26.5)$ & 0.4 \\
\hline No formal graduate research training & $109(39.2)$ & $76(52.1)$ & $39(29.5)$ & 0.002 \\
\hline Graduate Masters degree & $49(17.6)$ & $21(14.4)$ & $28(21.2)$ & 0.1 \\
\hline Research fellowship (e.g., HHMI, NIH) & $45(16.2)$ & $12(8.2)$ & $33(25.0)$ & 0.0001 \\
\hline Graduate doctoral degree & $25(9.0)$ & $14(9.6)$ & $11(8.3)$ & 0.7 \\
\hline Postdoctoral fellowship & $26(9.4)$ & $4(2.7)$ & $22(16.7)$ & 0.0001 \\
\hline \multicolumn{5}{|l|}{ Research presentations } \\
\hline Local institution & $210(75.5)$ & $106(72.6)$ & $104(78.8)$ & 0.2 \\
\hline Regional meetings & $157(56.5)$ & $67(45.9)$ & $90(68.2)$ & 0.0001 \\
\hline National meetings & $201(72.3)$ & $84(57.5)$ & $117(88.6)$ & 0.0001 \\
\hline International meetings & $63(22.7)$ & $20(13.7)$ & $43(32.6)$ & 0.0001 \\
\hline \multicolumn{5}{|l|}{ Research funding } \\
\hline Applied for neurosurgical research grant (value $<\$ 10,000$ ) & $70(25.2)$ & $15(10.3)$ & $55(41.7)$ & 0.0001 \\
\hline Received neurosurgical research grant (value $<\$ 10,000$ ) & $29(10.4)$ & $5(3.4)$ & $24(18.2)$ & 0.0001 \\
\hline Applied for neurosurgical research grant (value $\geq \$ 10,000$ ) & $58(20.9)$ & $14(9.6)$ & $44(33.3)$ & 0.0001 \\
\hline Received neurosurgery research grant (value $\geq \$ 10,000$ ) & $31(11.2)$ & $6(4.1)$ & $25(18.9)$ & 0.0001 \\
\hline Attitude toward research in neurosurgery during residency? & & & & 0.2 \\
\hline Encouraged & $138(49.6)$ & $66(45.2)$ & $72(54.5)$ & \\
\hline Neutral & $102(36.7)$ & $57(39.0)$ & $45(34.1)$ & \\
\hline Discouraged & $38(13.7)$ & $23(15.8)$ & $15(11.4)$ & \\
\hline
\end{tabular}

CNS $=$ Congress of Neurological Surgeons.

Data are reported as number (\%) unless otherwise indicated. Boldface type indicates statistical significance.

and $77.3 \%$ enjoyed participating in peer-reviewed research. A majority of residents (91.4\%) stated that clinical research or basic science research $(85.6 \%)$ was important in advancing neurosurgery. Overall, $75.9 \%$ agreed they would like to do more clinical research while only $40.6 \%$ stated they would like to do more basic science research.

Local institutional factors were assessed. Over half (57.2\%) of respondents agreed they had an adequate physical workspace for pursuing a research interest, and $78.8 \%$ reported that their program or department supported their research endeavor. Surprisingly, residents were divided regarding the role of funding as a major barrier to research: a total of $4.7 \%$ strongly disagreed, $28.1 \%$ disagreed, $32.0 \%$ were neutral, $25.9 \%$ agreed, and $8.3 \%$ strongly agreed that funding would be a major issue for future research. Residents were also split regarding time commitments, as $10.1 \%$ strongly disagreed, $30.2 \%$ disagreed, $27.3 \%$ were neutral, $28.4 \%$ agreed, and $2.9 \%$ strongly agreed that they have adequate time for research. Two-thirds of residents $(64.4 \%)$ agreed that important research could be performed in a private practice setting, and $70.7 \%$ agreed that important research could be done in all academic settings.

Comparison of AM and BM residents showed significant differences in their desire to continue research professionally $(p=0.003)$ or present research at local/national meetings $(p=0.02)$ and in their views toward the importance of research in future employment $(\mathrm{p}=0.01)$. In addition, AM residents were more interested in peer-reviewed $(\mathrm{p}=0.001)$ and specifically neurosurgical $(\mathrm{p}=0.007)$ research than BM residents. Importantly, AM residents significantly felt their programs supported their research compared with BM residents $(\mathrm{p}=0.04)$.

\section{Free-Response Questions}

Free-response questions served as a platform to identify issues affecting resident research as well as solutions to limiting factors (Table 4). Several themes from a regional/ national standpoint included improvements in collaboration, funding, data management, training/mentorship, regulatory/paperwork, and overall neurosurgical publications. 
TABLE 3. Limiting factors in neurosurgical resident research

\begin{tabular}{|c|c|c|c|c|}
\hline Limiting Factor & All Residents $(n=278)$ & BM Residents $(n=146)$ & AM Residents $(n=132)$ & p Value \\
\hline \multicolumn{5}{|l|}{ Important factors affecting interest in research } \\
\hline Mentorship & $257(92.4)$ & $130(89.0)$ & $127(96.2)$ & 0.07 \\
\hline Research exposure & $250(89.9)$ & $123(84.2)$ & $127(96.2)$ & 0.003 \\
\hline Early interest in science & $218(78.4)$ & $107(73.3)$ & $111(84.1)$ & 0.09 \\
\hline Interaction w/ my peers & $214(77.0)$ & $109(74.7)$ & $105(79.5)$ & 0.6 \\
\hline Specific patient questions arising during practice & $201(72.3)$ & $101(69.2)$ & $100(75.8)$ & 0.5 \\
\hline Neurosurgery conference exposure & $185(66.5)$ & $86(58.9)$ & $99(75.8)$ & 0.02 \\
\hline Formal research training prior to residency & $164(59.0)$ & $77(52.7)$ & $87(65.9)$ & 0.03 \\
\hline Mandated residency requirements & $132(47.5)$ & $70(47.9)$ & $62(47.0)$ & 0.98 \\
\hline \multicolumn{5}{|l|}{ Program support } \\
\hline Conference/travel support & $234(84.2)$ & $122(83.6)$ & $112(84.8)$ & 0.8 \\
\hline Protected research time & $196(70.5)$ & $104(71.2)$ & $92(69.7)$ & 0.8 \\
\hline Access to medical students \&/or undergraduates & $179(64.4)$ & $94(64.4)$ & $85(64.4)$ & 0.99 \\
\hline Internal funding sources & $126(45.3)$ & $57(39.0)$ & $69(52.3)$ & 0.05 \\
\hline Clinical study coordinator & $124(44.6)$ & $58(39.7)$ & $66(50.0)$ & 0.09 \\
\hline Collaborative agreements w/ other researchers & $121(43.5)$ & $61(41.8)$ & $60(45.5)$ & 0.5 \\
\hline Software support & $99(35.6)$ & $43(29.5)$ & $56(42.4)$ & 0.02 \\
\hline Time to obtain additional degrees/training & $90(32.4)$ & $42(28.8)$ & $48(36.4)$ & 0.2 \\
\hline Academic editor & $85(30.6)$ & $44(30.1)$ & $41(31.1)$ & 0.9 \\
\hline Medical illustrator & $74(26.6)$ & $34(23.3)$ & $40(30.3)$ & 0.2 \\
\hline \multicolumn{5}{|l|}{3 most limiting factors in pursuing research interest } \\
\hline Time & $253(91.0)$ & $131(89.7)$ & $122(92.4)$ & 0.4 \\
\hline Call schedule & $131(47.1)$ & $69(47.3)$ & $62(47.0)$ & 0.96 \\
\hline Funding/grants & $103(37.1)$ & $45(30.8)$ & $58(43.9)$ & 0.02 \\
\hline $\begin{array}{l}\text { Administrative assistance (e.g., clinical coordinator, } \\
\text { biostatistician, editor) }\end{array}$ & $100(36.0)$ & $48(32.9)$ & $52(39.4)$ & 0.3 \\
\hline Regulatory paperwork (e.g., IRB, IACUC, FDA) & $52(18.7)$ & $22(15.1)$ & $30(22.7)$ & 0.1 \\
\hline Finding novel research topics & $52(18.7)$ & $35(24.0)$ & $17(12.9)$ & 0.02 \\
\hline Lack of participating students or residents & $36(12.9)$ & $15(10.3)$ & $19(14.4)$ & 0.3 \\
\hline Lack of interest & $30(10.8)$ & $19(13.0)$ & $11(8.3)$ & 0.2 \\
\hline Training in the scientific method & $26(9.4)$ & $17(11.6)$ & $9(6.8)$ & 0.2 \\
\hline Institutional support & $24(8.6)$ & $17(11.6)$ & $7(5.3)$ & 0.06 \\
\hline Departmental encouragement & $14(5.0)$ & $7(4.8)$ & $7(5.3)$ & 0.8 \\
\hline
\end{tabular}

IACUC = Institutional Animal Care and Use Committee.

Data are reported as number (\%) unless otherwise indicated. Boldface type indicates statistical significance.

From a departmental standpoint, residents identified needs as resources for paperwork and data management, mentorship, funding, and time. Some residents requested changes in departmental attitudes toward research to encourage further research opportunities.

\section{Discussion}

Residents and practicing neurosurgeons share the conviction that clinical and basic science research underlies advancement of the field of neurosurgery, yet the means to that end continue to be debated. Although the underlying motivators of an individual's scientific curiosity may ultimately remain as varied as the individuals themselves, strategic interventions at the national or programmatic level may potentiate or dampen an individual's academic flame (Table 5). The results of this study confirm that residents enjoy participating in peer-reviewed research, and they possess a desire to continue pursuing it during their careers. Overall, half (49.6\%) of residents were encouraged toward pursuing research during their residency, the other half were either neutral $(36.7 \%)$ or discouraged (13.7\%) toward pursuing research. The three top limiting factors for resident research included adequate time, call scheduling, and funding. AM residents reported a greater number of devoted research hours weekly and more grant funding (external and internal grants), presentation of research, mentorship, and research exposure (prior to residency and during residency).

\section{Research Productivity}

Sarkiss et al. ${ }^{22}$ published a key study on neurosurgi- 


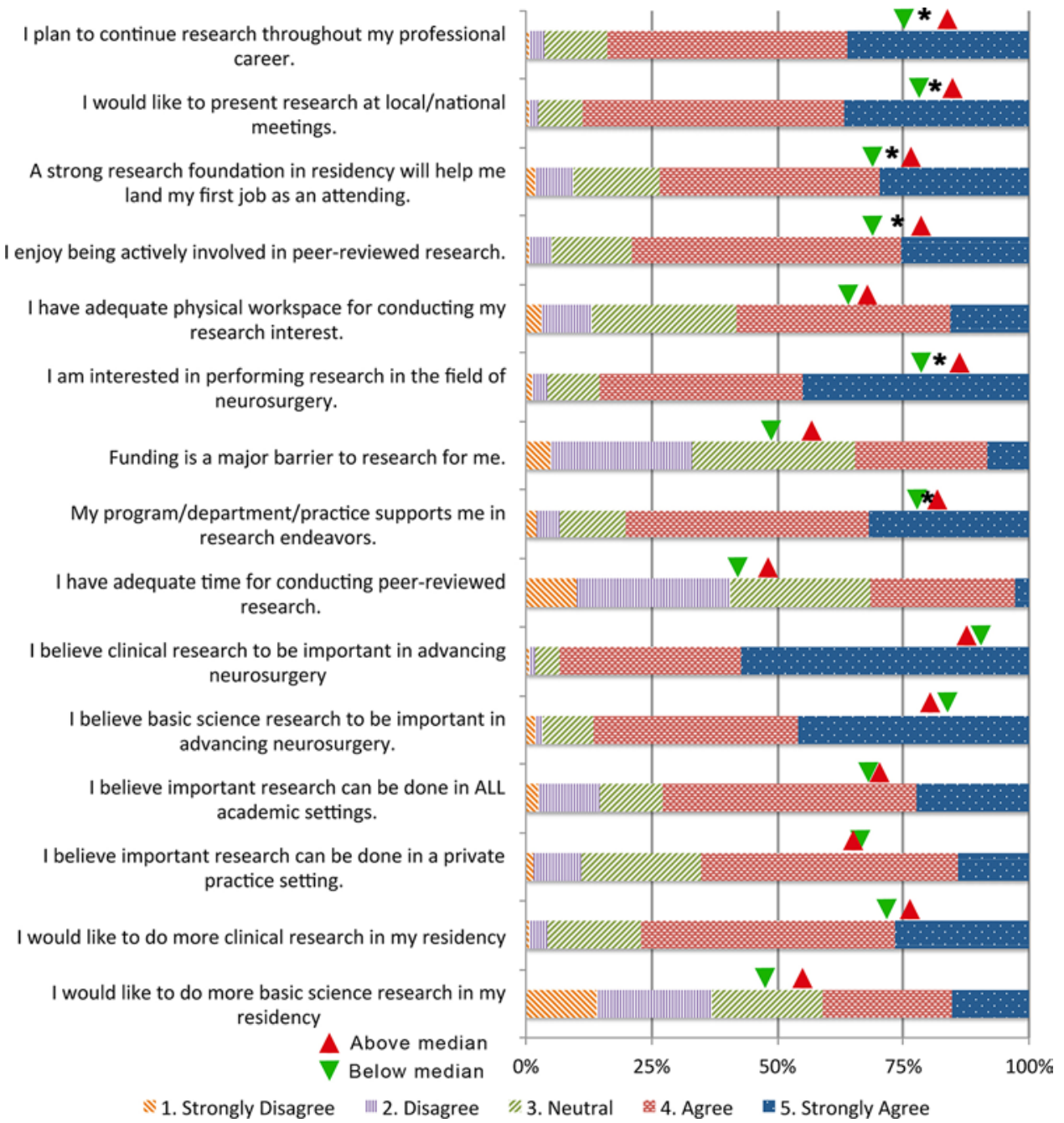

FIG. 3. Multiple-choice responses to agreement statements. Resident opinions for various question prompts were elicited on a 5-tier scale: strongly agree, agree, neutral, disagree, and strongly disagree. AM (triangle) and BM (inverted triangle) resident averages were compared by assigning weights of $0,25,50,75$, and 100 for respective responses, which were compared by t-test. *Significant difference at $p<0.05$. Figure is available in color online only.

cal research evaluating 1352 neurosurgical residents in 105 programs, comparing resident and faculty h-indices. Residents published a total of 2.9 first-author papers with a mean h-index of 2.47 and 7.6 documents in Scopus. Our results showed that residents published an average of 11 papers, suggesting that coauthored papers are a predominant part of resident portfolios. The top three subspecialties among resident publications (vascular, spine, and oncology) also correlated with the top three subspecialty career interests. Sarkiss et al. showed that larger program size and greater faculty and resident productivity each individually correlated with overall academic departmental productivity and ranking. Funding and research opportunities may be more available at larger programs. Sarkiss et al. showed that productivity between residents and faculty at the top-20 ranked programs did not correlate with the overall group or bottom-20 ranked programs. This suggested that residents were possibly involved in research independently or with nonneurosurgical faculty.
Some, but not all, studies have correlated residency research publication with further academic pursuits. Crowley et al. ${ }^{5}$ tracked 717 neurosurgical graduates between 1985 and 1990 and evaluated those that later pursued academic careers or were promoted to professor, chairs, or chiefs of neurosurgery compared with other neurosurgical careers. This study showed that those pursuing academics had a higher number of total publications (5.1 vs 1.9, p < $0.001)$ and first-author publications (3.0 vs 1.0, p < 0.001$)$ during residency. Program size ( $\geq 2$ graduates/year) correlated with an academic career but not professorship or serving as a chair/chief. Further studies in neurosurgery and other medical fields have shown a correlation between publication during residency and future academic productivity. ${ }^{16-18,24,28}$ However, this correlation between publication and future academic pursuits has not been shown in all studies, including for neurosurgical residents. ${ }^{13,21}$ Daniels et al. ${ }^{7}$ demonstrated that publications during residency, an h-index of $\geq 2$ achieved during residency, and devoted 
TABLE 4. Direct written responses from residents discussing needed support

\begin{tabular}{|c|c|}
\hline Category & Responses \\
\hline \multicolumn{2}{|c|}{ Regional/national aspects } \\
\hline Collaboration & $\begin{array}{l}\text { "Ability to do research at other institutions" } \\
\text { "Creation of broad collaborative initiatives between institutions" } \\
\text { "Greater inter-institutional research collaborations and data sharing possibilities" } \\
\text { "Organizational-led research initiatives for residents" } \\
\text { "I think more meeting time focused on getting residents together to discuss their research may help foster collaboration and } \\
\text { shared ideas looking into careers" } \\
\text { "Protected time for research; senior resident sharing research with juniors" } \\
\text { "Ability to have a protected research space and protected time with good collaboration with local university" }\end{array}$ \\
\hline Funding & $\begin{array}{l}\text { "Better NIH funding from the government" } \\
\text { "Conference travel funds" } \\
\text { "More grant opportunities" } \\
\text { "NREF is the only option that exists for the funding of neurosurgery residents and more of the funding is being funneled to young } \\
\text { attendings, which is really putting current residents at a distinct disadvantage" } \\
\text { "My hope would be that in the future we follow the HHMl approach and fund the applicant, not the project. Or, in the least, ex- } \\
\text { pand our funding mechanisms to favor resident-driven projects. Seed grants, to be used for material support rather than sala- } \\
\text { ries, are another option. These could be much smaller than the salary support for an NREF but have a tremendous impact" } \\
\text { "Junior-level funding opportunities" } \\
\text { "Small grants ( } \$ 5,000 \text { or less)" }\end{array}$ \\
\hline $\begin{array}{l}\text { Data manage- } \\
\text { ment }\end{array}$ & $\begin{array}{l}\text { "Access to the neurosurgical outcomes databases" } \\
\text { "More consortiums of centers to pool clinical data" } \\
\text { "A database to help have easy access to patient information" } \\
\text { "More longitudinal databases to pick and choose from" }\end{array}$ \\
\hline $\begin{array}{l}\text { Training/ men- } \\
\text { torship }\end{array}$ & $\begin{array}{l}\text { "Research training at national conferences, additional research courses/webinars/material to improve training with methodology, } \\
\text { grantsmanship, improved understanding about the direction that careers with neurosurgical research can take" } \\
\text { "Organized courses on writing grants" } \\
\text { "RUNN-type meetings" } \\
\text { "Statistics workshops, coding workshops, Photoshop/lllustrator workshops, grant-writing courses" } \\
\text { "Online resource for connecting with neurosurgical mentors across different institutions" }\end{array}$ \\
\hline $\begin{array}{l}\text { Regulatoryl } \\
\text { paperwork }\end{array}$ & "...collaboration with other labs/hospitals that have already approved research projects may make [IRB approval] easier" \\
\hline Publication & $\begin{array}{l}\text { "Higher barrier for bull**** research, and lower emphasis on quantity throughput. Then we could focus energies on fewer, high- } \\
\text { quality studies" }\end{array}$ \\
\hline \multicolumn{2}{|c|}{ Departmental aspects } \\
\hline $\begin{array}{l}\text { Departmental } \\
\text { resources }\end{array}$ & $\begin{array}{l}\text { "Medical writer to hold us accountable and teach us how to begin to publish" } \\
\text { "Administrative assistance that will help with documentation, finances, etc." } \\
\text { "A coordinator to help with the paperwork and regulator issues" } \\
\text { "A devoted research coordinator. Someone to help recruit and consent participants, help collect data" } \\
\text { "Academic editor and biostatistician" } \\
\text { "I have experienced } 3 \text { institutions during my residency (my residency, enfolded fellowship, and post-residency fellowship). By } \\
\text { FAR the most helpful resources to productivity are the presence of an editor and medical illustrator! Hands down" } \\
\text { "There is little time to efficiently go through data and statistics without the appropriate staff to help" }\end{array}$ \\
\hline Mentorship & $\begin{array}{l}\text { "Clinical and basic science faculty mentors who can act as clearinghouses for projects and ideas" } \\
\text { "... someone who knows how to apply for grants and plan prospective research" } \\
\text { "More introductory lectures/meetings for people who are entering residency who are entirely new to research. Basics like: how } \\
\text { to engage in meaningful research? What are grants and how do they work? What are some good mentored opportunities for } \\
\text { those new to research? etc." } \\
\text { "Specific research mentors to help devise research ideas and put together timelines. Currently, everything is very relaxed and } \\
\text { informal and thus a lot of good project ideas fall through the cracks" }\end{array}$ \\
\hline Funding & $\begin{array}{l}\text { "Resources to get funding for small projects" } \\
\text { "Funding, opportunity, time" }\end{array}$ \\
\hline
\end{tabular}


» CONTINUED FROM PAGE 260

TABLE 4. Direct written responses from residents discussing needed support

\begin{tabular}{l}
\hline Category \\
\hline Departmental aspects (continued) \\
\hline Time \\
"Time to go to conferences" \\
"Academic days during junior residency" \\
"Truly protected research time" \\
" will be continuing to pursue research during the protected research years; however, dedicated time during junior residency \\
"Longitudinal research time (e.g., 1-2 days over 2-3 years rather than 1 year of dedicated research), department faculty involve- \\
ment and encouragement of research endeavors. Funding sources" \\
"More administrative assistance given the overall demands of our clinical/operative duties" \\
"Time and clinical obligations are the most limiting steps in a research setting early on but are also non-negotiable components \\
of a neurosurgical residency" \\
"Change in attitude. Tell[ing] us to do it for years, hasn't happened, still take same approach" \\
"My department has been and continues to encourage my research interests and provides me with sufficient time and resources \\
to invest in my research"
\end{tabular}

pre-residency research time predicted a postresidency academic career. The number of pre-residency publications was not predictive of an academic career.

\section{Research Limiting Factors}

Although it is clear that there are limiting factors for resident research, there are also possible solutions. Jagannathan et al. ${ }^{10}$ suggested that the creation of an 80 -hour work week has limited time to devote to scholarly activities. This study showed that when comparing resident abstract presentation to the AANS annual meeting, the number of abstracts submitted by residents decreased from 345 abstracts in 2002 to 218 abstracts in 2007 ( $p<0.05$ ). Besides the limitation of available time and call schedules, funding and formalized training in the research process may have played a role in the lower number of abstract presentations. Funding has clearly been shown to impact research output but remains a significant challenge. ${ }^{9,25,27}$ Formal research training may be a more rectifiable issue. Eastwood et al. ${ }^{8}$ published a guide for improving resident academic pursuits. Strategies to improve research included a series of seminars and one-on-one tutorials with academic editors as well as training on the scientific publishing process. Such interventions could be easily replicated at other departments or at a national level. In addition, formalized research training during neurosurgical residency might improve critical analysis of the literature, which could improve overall clinical training for all residents. Mentor- ship, as shown by our study, is critical to guiding residents, increasing opportunities, and likely fostering interest in research during residency. Lastly, pre-residency training is important in fostering future scholarship. Choi et al. ${ }^{4}$ suggested that neurosurgical residents with doctoral training were more likely to hold academic medicine positions and to have received funding from the NIH. Our study suggests that postdoctoral training and other research fellowship training (e.g., Howard Hughes Medical Institute [HHMI], NIH) may be helpful in encouraging research endeavors. Formalized research education might not only help with resident education but also provide a holdover value for practicing neurosurgeons as they critically assess which new technologies and studies have really passed the rigor of proper evaluation.

Residents provided direct responses highlighting some of the many solutions to current research problems. Several common themes emerged, including collaboration, funding, data management, training/mentorship, regulatory/paperwork, and publication. Programs and attending physicians can work on actively pursuing collaboration with residents and modeling good collaboration with other colleagues. Although faculty with active laboratories may be able to better guide research endeavors with residents and influence research attitudes, faculty at all levels can serve as mentors. The creation of additional subspecialty registries could engage interested residents at different institutions to help with data management and analysis,

\section{TABLE 5. Survey conclusions}

\footnotetext{
1. Program directors \& chairs can implement strategies to minimize the 3 top limiting factors for resident research, which included adequate time, call scheduling, \& funding/grants, while improving factors to promote research, such as faculty mentorship \& exposure to research. Additional access to resources (e.g., database support, biostatisticians, medical editor) may help in the setting of limited time available for resident research.

2. National leaders should recognize that nonacademic neurosurgeons, i.e., those in private practice, may nonetheless wish to remain actively involved in research efforts that advance the field.

3. Academic departments w/ residency programs must hire \& cultivate faculty who are themselves academically productive \& committed to mentorship.

4. Resident neurosurgeons have a desire for cross-institutional collaboration. This is already facilitated in part by programs including RUNN \& the resident Boot Camps, but a collaborative national or international platform remains to be established.
} 
while building collaboration. The Young Neurosurgeons Committee would be an ideal level for organizing collaborative efforts for residents across institutions. Other potential environments where resident research can be fostered could include the junior resident boot camps, the RUNN course, and other resident courses. The British Neurosurgical Trainee Research Collaborative is one example of how collaboration is conducted successfully. ${ }^{3}$ It is also apparent that neurosurgeons of the next generation do not observe a sharp distinction between academic and privately practicing physicians; leaders of the field should utilize new mechanisms to harness research interests in neurosurgeons who may otherwise launch careers in a private practice setting.

Funding is a challenge at any level of research. National efforts to raise research funding via the Neurosurgery Research and Education Foundation (NREF) have been very successful. Increased opportunity for smaller grants, higher risk projects, and junior residents would be potential avenues that could pay dividends in encouraging resident research and opening opportunities for a wider range of residents. Improvement of resident research training on a national perspective could include resident seminars and courses on grant writing, forming an academic career, statistical analysis, scientific writing, and other relevant topics. Even if the pursuit of research interests and scholarship is not in the interest of every resident or residency program, the potential for learning the scientific method and critical appraisal of the literature is beneficial to all physicians.

The challenge in finding a balance between clinical and research endeavors is not new or unique to the field of neurosurgery. ${ }^{6,20}$ From a departmental standpoint, avenues for improving resident research are suggested. Additional departmental resources (i.e., clinical coordinator, databases, academic editors, biostatisticians) are critical as residents reported that time and clinical responsibilities are predominant limiting factors. Internal funding sources and small grants for junior residents are additional resources residents identify as important. Mentorship is crucial for residents to understand how to apply for funding, formulate research ideas, and draft manuscripts. Encouragement from departments, including support for conferences, protected research time, and high expectations, are also important factors.

\section{Study Limitations}

Some study limitations for this project should be addressed. Although the overall response to the survey was positive, multiple residency programs did not have responses and the overall response rate was $20 \%$. Regardless, because the questions were intended to examine both individual and programmatic factors, even one response from a program would provide an idea about the available resources. Responses to the survey may have been biased toward individuals more interested in research. Further follow-up with respondents and tracking of career direction would be helpful in evaluating research career aspirations. Resident research publications were self-reported and not verified, thus creating a potential recall/reporting bias. In addition, although the number of papers was quan- tified and presentation at conferences was evaluated, the number of abstracts and conference presentations were not counted. Number of publications is certainly a narrow measure of scholarly performance, as with any bibliometric measure, but can serve as a metric for future comparisons. Resident publication number did increase with PGY level as expected, and only a handful of outliers were identified, suggesting that self-reporting may be reasonably accurate. Our intention with the survey was not to rank programs against one another, thus limiting comparison of ranking to previous studies. We believe this ranking is detrimental to scholarly pursuits in neurosurgery, and we instead suggest that improvement of resident research can be achieved at all programs.

\section{Conclusions}

This study helps to identify resident-identified individual and programmatic factors affecting neurosurgical resident research. Factors both encouraging and limiting research are delineated. In addition, suggestions for improvement at national, regional, and departmental levels are suggested.

\section{Acknowledgments}

We thank Kristin Kraus, MSc, for her editorial assistance. This survey was funded by an unrestricted educational grant from the Medical University of South Carolina, Department of Neurosurgery resident research fund. We thank Dr. E. Antonio Chiocca with the Society of Neurological Surgeons research committee and members of the Council of State Neurological Societies for their thoughtful remarks.

\section{References}

1. Alotaibi NM, Ibrahim GM, Wang J, Guha D, Mamdani M, Schweizer TA, et al: Neurosurgeon academic impact is associated with clinical outcomes after clipping of ruptured intracranial aneurysms. PLoS One 12:e0181521, 2017

2. Borges NJ, Navarro AM, Grover A, Hoban JD: How, when, and why do physicians choose careers in academic medicine? A literature review. Acad Med 85:680-686, 2010

3. Brennan PM, Kolias AG, Joannides AJ, Shapey J, Marcus HJ, Gregson BA, et al: The management and outcome for patients with chronic subdural hematoma: a prospective, multicenter, observational cohort study in the United Kingdom. J Neurosurg 127:732-739, 2017

4. Choi BD, DeLong MR, DeLong DM, Friedman AH, Sampson JH: Impact of $\mathrm{PhD}$ training on scholarship in a neurosurgical career. J Neurosurg 120:730-735, 2014

5. Crowley RW, Asthagiri AR, Starke RM, Zusman EE, Chiocca EA, Lonser RR: In-training factors predictive of choosing and sustaining a productive academic career path in neurological surgery. Neurosurgery 70:1024-1032, 2012

6. Culican SM, Rupp JD, Margolis TP: Retaining clinicianscientists: nature versus nurture. Invest Ophthalmol Vis Sci 55:3219-3222, 2014

7. Daniels M, Garzon-Muvdi T, Maxwell R, Tamargo RJ, Huang J, Witham T, et al: Preresidency publication number does not predict academic career placement in neurosurgery. World Neurosurg 101:350-356, 2017

8. Eastwood S, Derish PA, Berger MS: Biomedical publication for neurosurgery residents: a program and guide. Neurosurgery 47:739-749, 2000

9. Hauptman JS, Chow DS, Martin NA, Itagaki MW: Research productivity in neurosurgery: trends in globalization, scientific focus, and funding. J Neurosurg 115:1262-1272, 2011 
10. Jagannathan J, Vates GE, Pouratian N, Sheehan JP, Patrie J, Grady MS, et al: Impact of the Accreditation Council for Graduate Medical Education work-hour regulations on neurosurgical resident education and productivity. J Neurosurg 110:820-827, 2009

11. Jamjoom AA, Wiggins AN, Loan JJ, Emelifeoneu J, Fouyas IP, Brennan PM: Academic productivity of neurosurgeons working in the United Kingdom: insights from the h-index and its variants. World Neurosurg 86:287-293, 2016

12. Khan NR, Thompson CJ, Taylor DR, Venable GT, Wham RM, Michael LM II, et al: An analysis of publication productivity for 1225 academic neurosurgeons and 99 departments in the United States. J Neurosurg 120:746-755, 2014

13. Lawton MT, Narvid J, Quiñones-Hinojosa A: Predictors of neurosurgical career choice among residents and residency applicants. Neurosurgery 60:934-939, 2007

14. Lee RP, Venable GT, Roberts ML, Parikh KA, Taylor DR, Khan NR, et al: Five-year institutional bibliometric profiles for 119 North American neurosurgical residency programs: an update. World Neurosurg 95:565-575, 2016

15. Lozano CS, Tam J, Kulkarni AV, Lozano AM: The academic productivity and impact of the University of Toronto Neurosurgery Program as assessed by manuscripts published and their number of citations. J Neurosurg 123:561-570, 2015

16. Macknin JB, Brown A, Marcus RE: Does research participation make a difference in residency training? Clin Orthop Relat Res 472:370-376, 2014

17. McClelland S III: Pre-residency peer-reviewed publications are associated with neurosurgery resident choice of academic compared to private practice careers. J Clin Neurosci 17:287-289, 2010

18. McClelland S III, Thomas CR Jr, Wilson LD, Holliday EB, Jaboin JJ: Association of preresidency peer-reviewed publications with radiation oncology resident choice of academic versus private practice career. Pract Radiat Oncol 7:364367,2017

19. National Resident Matching Program: Results and Data: 2017 Main Residency Match. Washington, DC: National Resident Matching Program, 2017 (http://www.nrmp.org/wpcontent/uploads/2017/06/Main-Match-Results-and-Data-2017. pdf) [Accessed May 1, 2018]

20. O'Brien J, D'Eon M: Re-thinking clinical research training in residency. Can Med Educ J 5:e58-e61, 2014

21. Prasad V, Rho J, Selvaraj S, Cheung M, Vandross A, Ho N: Can a resident's publication record predict fellowship publications? PLoS One 9:e90140, 2014

22. Sarkiss CA, Riley KJ, Hernandez CM, Oermann EK, Ladner TR, Bederson JB, et al: Academic productivity of US neurosurgery residents as measured by h-index: Program ranking with correlation to faculty productivity. Neurosurgery 80:975-984, 2017

23. Schoenfeld AJ, Bhalla A, George J, Harris MB, Bono CM: Academic productivity and contributions to the literature among spine surgery fellowship faculty. Spine J 15:21262131, 2015

24. Stern SA, Kim HM, Neacy K, Dronen SC, Mertz M: The impact of environmental factors on emergency medicine resident career choice. Acad Emerg Med 6:262-270, 1999

25. Svider PF, Husain Q, Folbe AJ, Couldwell WT, Liu JK, Eloy JA: Assessing National Institutes of Health funding and scholarly impact in neurological surgery. J Neurosurg 120:191-196, 2014

26. Taylor DR, Venable GT, Jones GM, Lepard JR, Roberts ML, Saleh N, et al: Five-year institutional bibliometric profiles for 103 US neurosurgical residency programs. J Neurosurg 123:547-560, 2015

27. Venable GT, Khan NR, Taylor DR, Thompson CJ, Michael LM, Klimo P Jr: A correlation between National Institutes of Health funding and bibliometrics in neurosurgery. World Neurosurg 81:468-472, 2014

28. Yang G, Zaid UB, Erickson BA, Blaschko SD, Carroll PR, Breyer BN: Urology resident publication output and its relationship to future academic achievement. J Urol 185:642646, 2011

\section{Disclosures}

Dr. Spiotta reports being a consultant to Penumbra, Cerenovus, and Minnetronix. Dr. Jensen reports being a consultant to Medtronic and Pharmokcokinesis.

\section{Author Contributions}

Conception and design: all authors. Acquisition of data: Karsy, Henderson. Analysis and interpretation of data: Karsy, Henderson. Drafting the article: Karsy, Henderson, Tenny. Critically revising the article: all authors. Reviewed submitted version of manuscript: all authors. Approved the final version of the manuscript on behalf of all authors: Karsy. Elicited funding: Karsy, Henderson.

\section{Supplemental Information}

\section{Online-Only Content}

Supplemental material is available with the online version of the article.

Supplemental Material 1. https://thejns.org/doi/suppl/10.3171/ 2018.3.JNS172846.

Supplemental Material 2. https://thejns.org/doi/suppl/10.3171/ 2018.3.JNS172846.

\section{Correspondence}

Michael Karsy: University of Utah, Salt Lake City, UT. neuropub@hsc.utah.edu. 